University of Nebraska - Lincoln

DigitalCommons@University of Nebraska - Lincoln

\title{
8-2009
}

\section{Adsorbate/absorbate interactions with organic ferroelectric polymers}

Peter A. Dowben

University of Nebraska-Lincoln, pdowben@unl.edu

Luis G. Rosa

University of Puerto Rico-Humacao, luis.rosa13@upr.edu

Carolina C. Ilie

State University of New York at Oswego

Jie Xiao

University of Nebraska-Lincoln, jie.xiao@helmholtz-berlin.de

Follow this and additional works at: https://digitalcommons.unl.edu/physicsdowben

Part of the Physics Commons

Dowben, Peter A.; Rosa, Luis G.; Ilie, Carolina C.; and Xiao, Jie, "Adsorbate/absorbate interactions with organic ferroelectric polymers" (2009). Peter Dowben Publications. 232.

https://digitalcommons.unl.edu/physicsdowben/232

This Article is brought to you for free and open access by the Research Papers in Physics and Astronomy at DigitalCommons@University of Nebraska - Lincoln. It has been accepted for inclusion in Peter Dowben Publications by an authorized administrator of DigitalCommons@University of Nebraska - Lincoln. 
Published in Journal of Electron Spectroscopy and Related Phenomena 174:1-3 (August 2009), pp. 10-21;

special issue on "Advanced Spectroscopies of Molecular Materials for Electronics"; doi: 10.1016/j.elspec.2009.03.005

Copyright () 2009 Elsevier B.V. Used by permission. http://www.elsevier.com/locate/elspec

Published online March 24, 2009.

REVIEW

\title{
Adsorbate/absorbate interactions with organic ferroelectric polymers
}

\author{
P. A. Dowben, ${ }^{a}$ Luis G. Rosa, ${ }^{b}$ Carolina C. Ilie, ${ }^{c}$ and Jie Xiao ${ }^{a}$ \\ a Department of Physics and Astronomy and The Nebraska Center for Materials and Nanoscience, \\ University of Nebraska-Lincoln, Lincoln, NE 68588-0111, USA \\ ${ }^{\mathrm{b}}$ Department of Physics and Electronics, University of Puerto Rico-Humacao, \\ 100 Road \#908, CUH Station, Humacao, PR 00791, USA \\ ' Department of Physics, State University of New York at Oswego, Oswego, NY 13126, USA \\ Corresponding author - Peter A. Dowben, tel 402 472-9838, fax 402 472-2879, email pdowben@unl.edu
}

\begin{abstract}
We discuss the interactions of adsorbates with the organic ferroelectric copolymer poly(vinylidene fluoride (PVDF)-trifluoroethylene (TrFE)). Range of molecular adsorbates is discussed from the smaller polar molecules like water, which is small enough to both adsorb and absorb, to the larger macrocyclic metal-organic metal phthalocyanines. The changes in local dipole orientation may affect the strength of the coupling between adsorbate or absorbate and the copolymer poly(vinylidene fluoride-trifluoroethylene). The interface dipole interactions may also affect device properties. The dipole interactions are implicated at the interface between copper phthalocyanine and poly(vinylidene fluoride with trifluoroethylene) affecting the band offsets and the diode properties.
\end{abstract}

Keywords: ferroelectric polymers, molecular adsorption, interface dipoles, molecular orbital offsets, HOMO-LUMO gap, molecular electronic structure

\section{Contents}

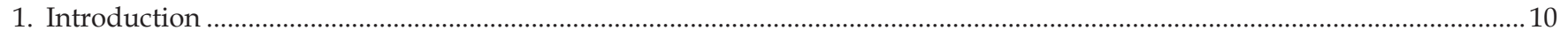

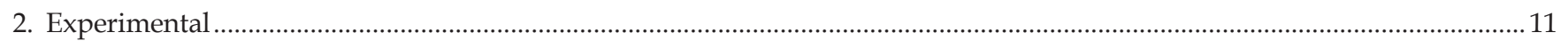

3. Metastable interface states and photo-enhanced thermal desorption of water from an organic ferroelectric............................ 12

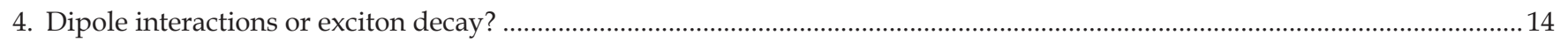

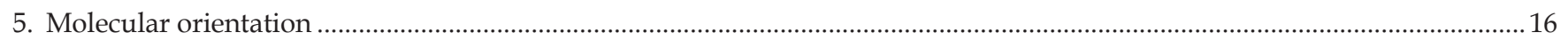

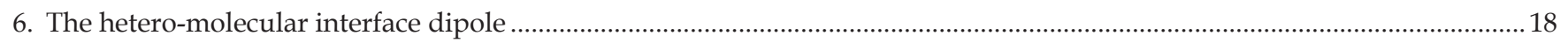

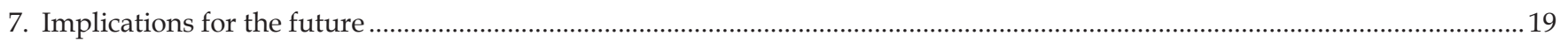

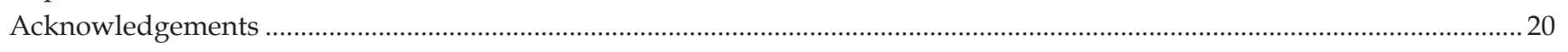

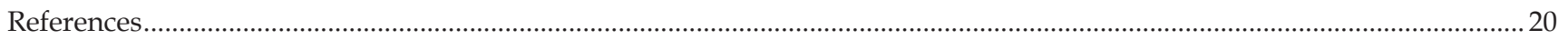

\section{Introduction}

Surface dipole interactions have long been implicated as important in surface adsorption and surface catalysis [1-4]. The investigation of surface dipole interactions are, unfortunately, often complicated by the influence of the substrate (including band structure effects [5]) and strong perturbations due to surface charges that induce large surface dipoles on metal surfaces [6]. Ferroelectric materials provide a great opportunity to investigate dipole interactions with adsorbates [7-32], particularly as the surface electric dipoles are "reversible" [7, 8, 11-18, 27-29, 32-46].

Our preference for crystalline polymer ferroelectric materials [19-48] as a substrate for the study of adsorbate interactions with surface dipoles stems from their surprising simplicity compared to the complex surfaces formed with the inorganic ferroelectric materials. The complexities associated with inorganic ferroelectrics include surface compositional instabilities, an abundance of lattice defects (point defects, steps and grain boundaries), and 




Figure 1. The surface structure of crystalline P(VDF-TrFE) Langmuir-Blodgett films as ascertained from scanning tunneling microscopy. The scanning tunneling microscope images, recorded at $295 \mathrm{~K}$, are of nominally 2 monolayer thick film on graphite substrates, with $4.4 \mathrm{~nm} \times 4.4 \mathrm{~nm}$ image size. In the inset is the atomically resolved STM image of the surface of P(VDF-TrFE 70:30) film on graphite at room temperature, obtained at higher bias $(-0.36 \mathrm{~V}$ instead of $-0.1 \mathrm{~V})$ and the surface unit cell is also indicated. Every bright spot represents a $\mathrm{CH}_{2}-\mathrm{CF}_{2}-$ or $-\mathrm{CHF}-\mathrm{CF}_{2}-$ monomer. Adapted from [27, 33, 34, 45].

considerable difficulty in preparing a stable reproducible surface with well-ordered dipoles oriented along the surface normal. We have undertaken extensive investigations of adsorbate interactions with poly(vinylidene fluoride (PVDF)-trifluoroethylene (TrFE)) copolymers, a uniquely crystalline polymer system [19-21, 24, 25, 27, 32-47].

Poly(vinylidene fluoride) [PVDF, $-\left(\mathrm{CH}_{2}-\mathrm{CF}_{2}\right)_{n}-$ ] copolymers with trifluoroethylene [TrFE, $\left.-\left(\mathrm{CHF}-\mathrm{CF}_{2}\right)-\right]$ can form highly ordered crystalline ferroelectric polymer ultrathin films as has been demonstrated by X-ray and neutron scattering $[19,20,22,35,37,38$, 40], scanning tunneling microscopy [27, 33-37, 39, 40, 42, 45, 46], low energy electron diffraction [36, 37] and band mapping [27, 36, $37,46]$. Although not always evident in scanning tunneling microscopy (Figure 1), the band structure shows a characteristic super-periodicity dominated by $-\left(\mathrm{CH}_{2}-\mathrm{CF}_{2}\right)_{2}-$ or $-\left(\mathrm{CH}_{2}-\mathrm{CF}_{2}\right)-\left(\mathrm{CHF}-\mathrm{CF}_{2}\right)-$ "dimer" pairs $[36,37,46]$ in the ferroelectric phase. The copolymer $\mathrm{P}(\mathrm{VDF}-\mathrm{TrFE}, 70: 30)$, in spite of the low overall symmetry, does show all the characteristics of high local symmetry and symmetry selection rules, with the dipoles aligned along the surface normal $[43,44]$. The effects are quite significant in photoemission [43, 44, 47] and electron energy loss spectroscopy [38, 43, 44, 48].

Our goal has been to obtain a detailed understanding of dipole interactions between small adsorbates and the ferroelectric polymer substrate. Fundamental surface science experiments are possible using our polymer systems because: (1) they are ultrahigh vacuum compatible, (2) the surfaces of the polymers are crystalline with a well defined structure and orientation, (3) the polymer films can be grown thin and uniform so the surface can be uniformly heated (and cooled) to well defined temperatures, and (4) the ferroelectric polymer thin films can be grown without pinholes or a large mosaic spread of different structural domains. Based on our recent results, we have good reason to believe we can now go well beyond the recently developed fundamental understand- ing that has come from our research efforts and construct organic multilayers systems that exhibit new phenomena like novel electronically driven phase transitions.

\section{Experimental}

Ultrathin ferroelectric films of copolymer $70 \%$ vinylidene fluoride with 30\% trifluoroethylene, P(VDF-TrFE 70:30) were fabricated by Langmuir-Blodgett (LB) deposition techniques on graphite substrates from the water subphase [19-25, 27-29, 31-45, 47]. The P(VDF-TrFE 70:30) films, nominally some 3-7 molecular layers thick (15-35 $\AA$ thick, as noted) were prepared in ultrahigh vacuum by annealing at $110^{\circ} \mathrm{C}$, which has proven to be an effective recipe in prior studies [19, 22-29, 31-41, 43-45, 47] and has been demonstrated to results in a surface free from impurities (including water) [48]. Thin films of short chain poly(vinylidene fluoride) were also prepared by vacuum evaporation [30,48], particularly for the fabrication of the bimolecular heterostructures (i.e. PVDF/ metal phthalocyanine heterostructures), as described elsewhere [30]. Films used for this study were nominally $20 \mathrm{~mL}(10 \mathrm{~nm})$ thick and grown on highly ordered pyrolytic graphite (HOPG) substrates, unless noted otherwise.

The thermal desorption spectra were obtained by annealing the graphite substrate resistively, and exploiting our ability to make films of $\mathrm{P}(\mathrm{VDF}-\mathrm{TrFE}$ 70:30) sufficiently thin to obtain the necessary thermal conductivity through the polymer thin film. Angle-resolved thermal desorption measurments were taken as described elsewhere $[19,22,25-27,49,50]$, with a differentially pumped mass spectrometer, and the angles denoted with respect to the surface normal.

Laser-assisted thermal desorption, creating metastable excited states during thermal desorption, was also undertaken. These experiments involved obtaining thermal desorption spectra while the surface was illuminated with a pulsed nitrogen gas laser $(337 \mathrm{~nm}, 3.66 \mathrm{eV})$, at $20 \mathrm{~Hz}$ with an intensity of $120 \mu \mathrm{J} /$ pulse [25, $27,50]$. The incident $337 \mathrm{~nm}$ radiation was polarized using a UV polarizer and focused onto the entire surface area of the sample (less than $2 \mathrm{~cm}^{2}$ ). In our laser assisted thermal desorption experiments, we compare two different incident light polarizations: linearly polarized light with the electric field vector $\mathbf{E}$ and the vector potential $\mathbf{A}$ of the incident radiation parallel with the surface and a polarization with the electric field vector $\mathbf{E}$ and the vector potential $\mathbf{A}$ of the incident radiation perpendicular to the surface, but with the same radiation intensity/area and no change in light incidence angle, as described elsewhere [25, 27, 50]. The desorbing species were collected normal to the film for both thermal desorption and photo-assisted thermal desorption studies, unless stated otherwise. Because of the very low UV flux densities, we employed a very low heating rate. The heating rates for obtaining the thermal desorption spectra (TDS) were $0.5 \%$ throughout this work. Faster heating rates are possible, but the concerns about thermal conductivity through the thicker polymer films precluded their use.

Inverse photoemission (IPES) was undertaken using a variable energy electron gun producing electron kinetic energies from 5 to $19 \mathrm{eV}$, incident normal to the surface. Photons were detected with a Geiger-Müller detector, as done in previous studies [22, 25, 27$31,35-37,41,45,50]$. The instrumental line width for inverse photoemission is $\sim 400 \mathrm{meV}$. Angle-resolved photoemission spectra were undertaken using synchrotron radiation generally at photon energies of 35 and $55 \mathrm{eV}$ (unless otherwise stated), dispersed by a $3 \mathrm{~m}$ toroidal grating monochromator [51], at the Center for Advanced Microstructure and Devices in Baton Rouge, Louisiana [52], employing a hemispherical electron energy analyzer with an angular acceptance of $\pm 1^{\circ}$. In both photoemission (UPS) and inverse photoemission (IPES) measurements, the binding energies are referenced 
with respect to the Fermi edge of gold or tantalum, in intimate contact with the sample surface.

Water and bromoform exposures are denoted in Langmuirs where $1 \mathrm{~L}=10^{-6}$ Torr $\mathrm{s}$ with exposure to $\mathrm{P}(\mathrm{VDF}-\mathrm{TrFE}$ 70:30) at 120-135 K. The metal $\left(\mathrm{Co}^{2+}, \mathrm{Ni}^{2+}\right.$, and $\left.\mathrm{Cu}^{2+}\right)$ phthalocyanines were evaporated onto evaporated poly(vinylidene fluoride) (PVDF) substrates at room temperature, as described elsewhere [28-30, 53], except where otherwise noted.

\section{Metastable interface states and photo-enhanced thermal de- sorption of water from an organic ferroelectric}

The connection between the bulk ferroelectric phase transition and the adsorption capacity of the adsorbent was observed for water on 7-11 monolayers thin films of polyvinylidene fluoride [16, 17]. A capacitance model for the estimation of water uptake in polymer PVDF coatings and thin films was presented [15] that is consistent with our own studies of the dielectric properties of P(VDFTrFE 70:30) [19, 21]. Such studies implicate a dipole interaction between water and the ferroelectric polymer dipoles [27]. The surface plays a role nonetheless. Surface dipoles can affect the binding site of water species adsorbed at the surface and sterically hinder or enhance desorption of adsorbed and absorbed water. Perturbations of local surface dipoles can affect desorption of absorbed water $[19,25,27]$. As we are dealing with polymers, the absorption of water is persistent, even with largely hydrophobic polymers. The grand complication is that with the absorption of water, the polymer lattice strain plays an important role [49]. The polymer lattice strain [19] that occurs with the absorption of water into the crystalline lattice of $\mathrm{P}(\mathrm{VDF}-\mathrm{TrFE} 70: 30)$ is not so noticeable with water desorption from the crystalline thin films of $\mathrm{P}(\mathrm{VDF}-\mathrm{TrFE}$ 70:30) [27], as it is observed with other polymers [27, 49].

From thermal desorption [21-27] and X-ray diffraction [19, 20, 22] studies, we find evidence that water is absorbed into the thin film bulk of the copolymers. The thermal desorption spectra of water from $\mathrm{P}(\mathrm{VDF}-\mathrm{TrFE}$ 70:30) are shown in Figure 2. Following exposure of water to crystalline thin films of P(VDF-TrFE 70:30) at $120-135 \mathrm{~K}$, the thermal desorption spectra are largely characterized by two desorption peaks, and reported elsewhere [21-25, 27]. Desorption of water at $150-160 \mathrm{~K}$ is characteristic of a water ice thin film sublimation (from the surface of P(VDF-TrFE 70:30). It is important to note that the desorption of this water ice like species is not observed with small exposures of water to the P(VDFTrFE) thin film samples cooled to $130 \mathrm{~K}$. For P(VDF-TrFE) samples roughly $15 \AA$ thick, more than 10 Langmuirs are required for evidence of ice formation from thermal desorption, as seen in Figure 2. For thicker films, greater exposures to water are required for the formation of ice. This is evident from the thermal desorption spectra [21-25, 27], and indicated in Figure 2b for P(VDFTrFE) samples roughly $35 \AA$ thick. Because the desorption temperature of water from $\mathrm{P}(\mathrm{VDF}-\mathrm{TrFE})$ above $280 \mathrm{~K}$ is associated with film thickness and water exposure, we associate this water species largely with absorbed water [22, 23, 25, 27], but a surface species cannot be completely excluded [23, 25, 27].

For the thinner P(VDF-TrFE 70:30) samples roughly $15 \AA$ thick or less, the thermal desorption spectra do provide an indication of a molecular water species at the surface that is significantly different from the absorbed water (Figure 2). There is a thermal desorption feature at $280-320 \mathrm{~K}$ in addition to a thermal desorption feature that begins at about $350 \mathrm{~K}$, as seen in Figure 2 [22, 25, 27]. As the $\mathrm{P}(\mathrm{VDF}-\mathrm{TrFE} 70: 30)$ sample thickness increases, the water thermal desorption feature at $280 \mathrm{~K}$ to $320 \mathrm{~K}$ is increasingly more difficult to observe $[22,25,27]$, but for the thinner films of P(VDFTrFE 70:30), this thermal desorption feature shows evidence of steric effects [19, 22, 25, 27]. By using thicker P(VDF-TrFE 70:30) thin films, where the steric effects in water desorption are not so readily apparent, there are several indicators that photo-enhanced

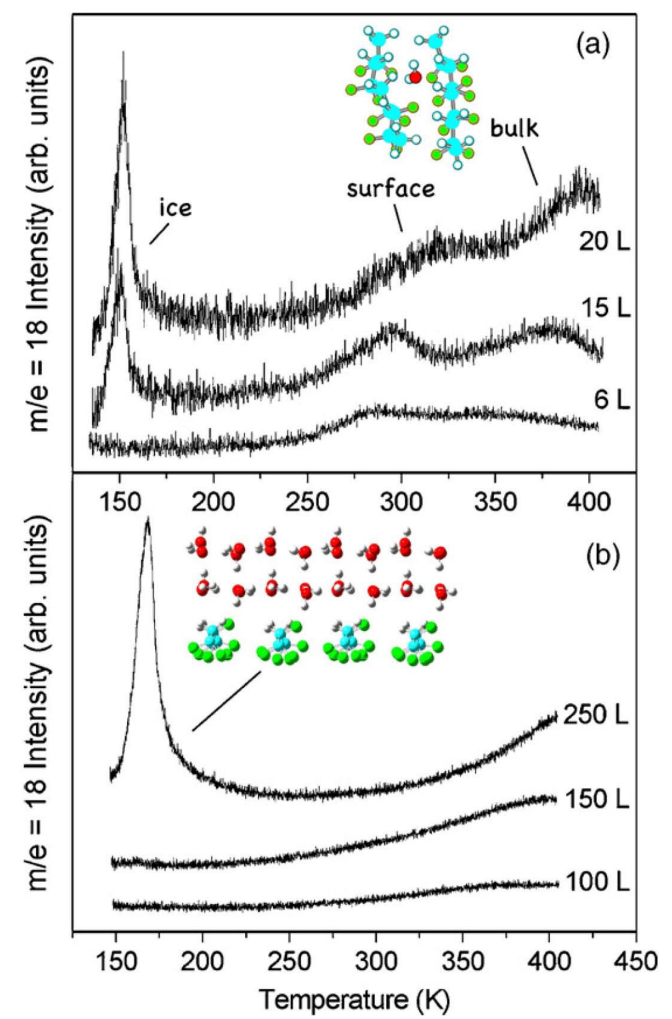

Figure 2. Thermal desorption spectra (TDS) of water from a thin $(15 \AA$ thick) $\mathrm{P}(\mathrm{VDF}-\mathrm{TrFE} 70: 30)$ on graphite for 6,15 and $20 \mathrm{~L}$ of exposure to water at $130 \mathrm{~K}\left(1 \mathrm{~L}=1 \times 10^{-6}\right.$ Torr s) is shown (a). Thermal desorption spectra (TDS) of water from a thicker ( $35 \AA$ thick) P(VDF-TrFE 70:30) on graphite for 100,150 and $250 \mathrm{~L}$ of exposure to water at $130 \mathrm{~K}$ $\left(1 \mathrm{~L}=1 \times 10^{-6}\right.$ Torr s) is shown (b). The assignment of the thermal desorption features to water ice $(150 \mathrm{~K})$ and absorbed water in P(VDF$\mathrm{TrFE})(300 \mathrm{~K})$ are indicated by the schematic minimum energy structures in (a), with the adsorbed surface water likely contributing to the thermal desorption feature at about $300 \mathrm{~K}$ in (a) and absorbed water contributing to the thermal desorption of water at even higher temperatures (see text). Adapted from [25, 27]. In the molecular schematics, blue is carbon, green fluorine, red oxygen.

thermal desorption of water from the ferroelectric $\mathrm{P}(\mathrm{VDF}-\mathrm{TrFE}$ 70:30) is an activated process.

Evidence for the influence of either dipole interactions or the preferential orientation of an adsorbed water species can be found in laser assisted thermal desorption. As seen in Figure 3, the thermal desorption of water is seen to be dependent on the light polarization of the incident radiation on the P(VDF-TrFE 70:30) [25, 27]. With $\mathbf{E}$ of the incident light parallel with the surface, the thermal desorption of absorbed water is promoted [25] for smaller water exposures (200-250 L) to a $35 \AA$ P(VDF-TrFE 70:30) thick film (following the initial adsorption at 120-135 K). The light enhanced thermal desorption occurs at a lower temperature with the incident light $\mathbf{E}$ parallel with the surface as compared to the light enhanced thermal desorption spectra of water taken with the $\mathbf{E}$ of the incident light parallel with the surface normal. With higher water exposures (and coverages) to P(VDF-TrFE 70:30), this effect with respect to the incident light polarization is lost (Figure $3 c$ ) and then reversed (Figure 3d). Since the UV laser light intensity is unaltered in these experiments, and only the light polarization is changed, light polarization is clearly an important factor. It is likely that changes in local dipole orientation and the formation of long-lived metastable states affects the heats of adsorption and desorption $[25,27]$. The photo-excitation and subsequent electron attachment to water or the polymer substrate surface to form 


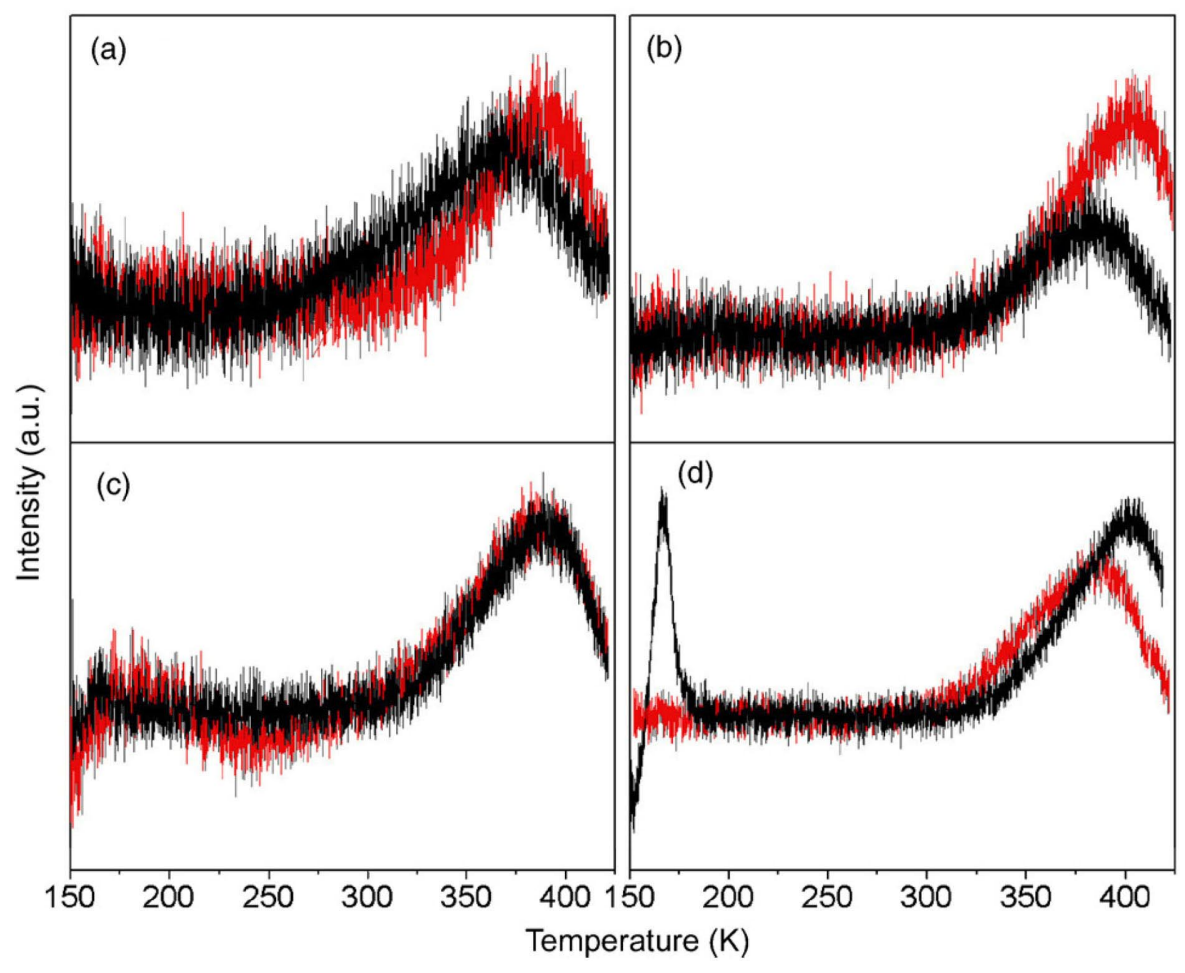

Figure 3. Laser assisted thermal desorption for: (a) $200 \mathrm{~L}$, (b) $250 \mathrm{~L}$, (c) $300 \mathrm{~L}$, and (d) $350 \mathrm{~L}$ of water exposure. The experiments were undertaken with incident light polarized with E parallel with film surface (black) and E parallel with the surface normal (red). Desorption of water was measured along the surface normal. Adapted from [25, 27].

$\mathrm{H}_{2} \mathrm{O}^{-}$or $\left[-\mathrm{CH}_{2}-\mathrm{CF}_{2}-\right]^{-}$may also occur, though energy considerations make this unlikely for the absorbed water directly [25].

This use of a UV laser to excite electrons from the graphite substrate into the ferroelectric polymer P(VDF-TrFE 70:30) implicates dipole orientation and dipole excitations in water thermal desorption [25, 27]. This light polarization dependent promotion of water desorption from $\mathrm{P}(\mathrm{VDF}-\mathrm{TrFE} 70: 30)$ is not simply a light induced effect alone $[25,27]$. The light enhanced thermal desorption of absorbed water from another dipole oriented polymer, poly(methylvinylidene cyanide) where dipole rotation is sterically hindered, shows only a small light polarization dependence in the light enhanced thermal desorption of water $[27,50]$. In the case of poly(methylvinylidene cyanide), the light polarization dependence in the UV light enhanced thermal desorption of water might well be due to Fresnel boundary conditions [50], while such Fresnel boundary considerations can be excluded as having a dominant role in the case of water desorption from P(VDF-TrFE 70:30) in the low water exposure regime [25].

We find that water desorption from P(VDF-TrFE 70:30) is not generally an activated process. UV light enhanced thermal desorption of water from $\mathrm{P}(\mathrm{VDF}-\mathrm{TrFE}$ 70:30) is an activated process judging from the angle-resolved thermal desorption studies, consistent with our expectations [27]. The integrated desorption intensities of absorbed water from a thin, nominally 5 monolayer thick (25 ̊ thick), P(VDF-TrFE 70:30) film are presented in Figure 4, as a function of desorption angle. In the absence of UV illumination, the normalized integrated water desorption intensity peaks along the surface normal (i.e. near $0^{\circ}$ with respect to the surface normal) for the slightly thicker $25 \AA$ thick P(VDF-TrFE 70:30) films. Integrated water desorption from $\mathrm{P}(\mathrm{VDF}-\mathrm{TrFE}$ 70:30) follows the $\cos ^{n} \theta$ distribution expected from simple phonon mediated desorption. We find the best fit corresponding to the $n=1.38$ (Figure 4).

The preference for the adsorbed water species to desorbs normal to the surface is enhanced when angle resolved thermal desorp- tion is undertaken in the presence of UV illumination (Figure 4). In contrast, the integrated water desorption intensities obtained from the thermal desorption spectra with and without the $337 \mathrm{~nm}$ UV illumination suggests that UV illumination causes deviations from the expected $\cos ^{n} \theta$ distribution [54-56]. The result is an angular dependence of water desorption, from P(VDF-TrFE) following an exponential decaying function $\exp (-\theta / \xi)$, with $\xi=26$. Deviations

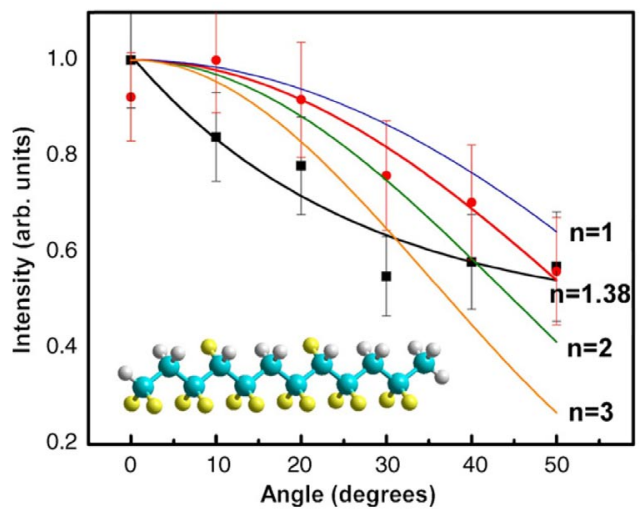

Figure 4. The integrated intensity of water desorbing from P(VDFTrFE) as a function of the angle with respect to the surface normal is shown following 5 Langmuirs of water exposure to $25 \AA$ thick P(VDFTrFE) thin film and follows the expected behavior from a simple phonon model: $\cos ^{n} \theta$, with the best fit corresponding to $n=1.38$ (red). The curves corresponding to $\cos ^{n} \theta$, where $n \in\{1,2,3\}$ are also shown for comparison. The integrated intensity of water desorbing from $\mathrm{P}(\mathrm{VDF}-$ $\mathrm{TrFE}$ ) enhanced by illumination with $337 \mathrm{~nm}$ UV radiation, with $\mathbf{E}$ in the plane of the film as shown in black follows an exponential decay with increasing angle. In the inset is seen $\mathrm{P}(\mathrm{VDF}-\mathrm{TrFE})$ polymer $\mathrm{CH}_{2}-$ $\mathrm{CF}_{2}$ : $\mathrm{CHF}-\mathrm{CF}_{2}$ 70\%:30\% by molecular percent, where $\mathrm{C}$, blue; $\mathrm{F}$, yellow; $\mathrm{H}$, white. Adapted from [27]. 


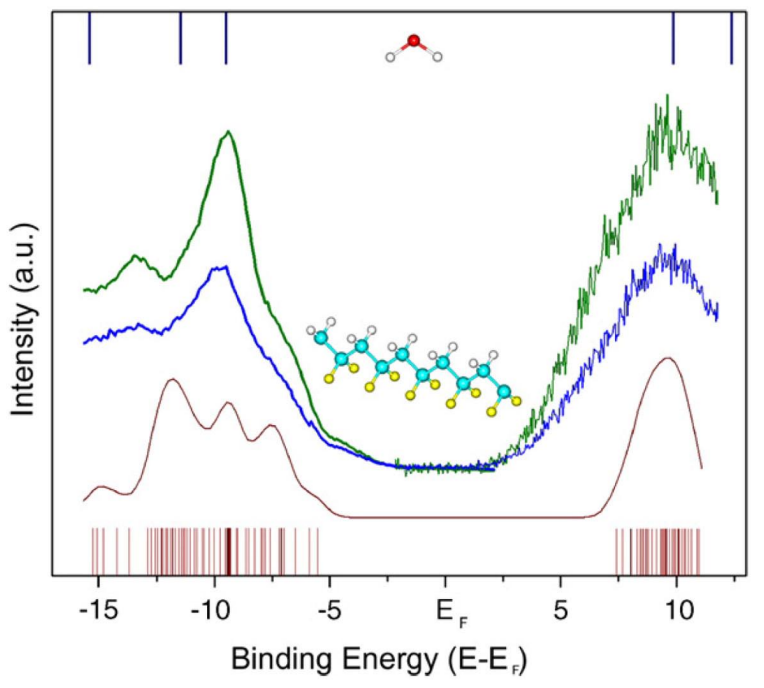

Figure 5. Combined photoemission (left) and inverse photoemission (right) spectra of $\mathrm{P}(\mathrm{VDF}-\mathrm{TrFE})$ thin films (15-20 ̊ thick) on graphite (green) are compared to P(VDF-TrFE) following exposure to 200 Langmuirs of water at $190 \mathrm{~K}$ (blue). For reference, a calculated density of states (DOS) of $\mathrm{P}(\mathrm{VDF}-\mathrm{TrFE})$ is shown, obtained by applying equal Gaussian envelopes of $1 \mathrm{eV}$ full width half maximum to each molecular orbital (shown at the bottom) calculated using a semiempirical PM3 methodology [25], to account for the solid state broadening in photoemission, and then summing. The calculated electronic states of water are at the top of the panel. All values are in eV. Adapted from [25].

from the expected $\cos ^{n} \theta$ distribution (where $\theta$ is the angle off normal and $n$ is the critical coefficient, which may vary between 1 and $4.5[55,56]$, and with values possibly as high as 9 [54]) in angle-resolved thermal desorption, can be indicative of an activated process. Given that strong light polarization effects in ultraviolet laser enhanced thermal desorption of absorbed water from poly(vinylidene fluoride-trifluoroethylene) have been observed [25], as discussed above, deviations from the expected $\cos ^{n} \theta$ distribution should be expected with water desorption from $\mathrm{P}(\mathrm{VDF}-\mathrm{TrFE})$ in the presence of the same UV radiation. Water desorption from $\mathrm{P}(\mathrm{VDF}-\mathrm{TrFE})$ should be an activated process in the presence of $337 \mathrm{~nm}$ radiation, when the electric vector is in the plane of the surface. We can now call this an extrinsic activation of water desorption [27].

The $3.66 \mathrm{eV}$ photon energy used in the UV light enhanced thermal desorption of water from $\mathrm{P}(\mathrm{VDF}-\mathrm{TrFE} 70: 30)$ is more than enough to excite electrons into the unoccupied states of P(VDF$\mathrm{TrFE}$ ) or $\mathrm{H}_{2} \mathrm{O}$ from the Fermi level of graphite. Such excitations from a conducting substrate to a molecular adsorbate are predicted for $\mathrm{CO}$ on $\mathrm{Pt}(111)$ [57] and water on graphite [58], for example. The cross-section for the absorption of UV radiation by both P(VDF-TrFE) [59] and water [60] is low, hence our expectation that the electron initial state is from graphite. UV light induced photoisomerization, likely due to exciton formation or an isolated carrier excitation, is known in other systems as in the photoisomerization from trans-stilbene and cis-stilbene [61]. This UV light induced photoisomerization is similar to the transition from the all trans configuration of ferroelectric $\mathrm{P}(\mathrm{VDF}-\mathrm{TrFE})$ to the trans-gauche configuration of paraelectric $\mathrm{P}(\mathrm{VDF}-\mathrm{TrFE})$.

We believe that either change in the dipole orientation or the changes in electronic structure caused by UV irradiation induced excitations enhance the desorption of water from the surface of $\mathrm{P}(\mathrm{VDF}-\mathrm{TrFE})$. If this is the case, then the likely mechanism for the polarization dependent light stimulated thermal desorption of absorbed water is electron (carrier) excitation from the graphite substrate accompanied by a metastable dipole reorientation of the polymer $[25,27]$ and this should be accompanied by a change in the density of states, as is observed [25]. We know from scanning tunneling microscopy studies that changing the applied bias will alter the dipole orientation $[33,34]$ and this observation is at least consistent with our belief that charge attachment may well lead to long-lived state with dipole reorientation(s).

There is evidence of a UV light induced change in the density of states. The combined photoemission and inverse photoemission spectra of $\mathrm{P}(\mathrm{VDF}-\mathrm{TrFE} 70: 30)$ are consistent with a wide band gap insulator and theoretical expectations [25]. Strong alterations of the P(VDF-TrFE 70:30) electronic structure are not observed with water absorption, as seen in Figure 5. With semiempirical molecular orbitals calculations by PM3-NDO (neglect of differential overlap) of hydrogen terminated (to prevent excessive folding) $\mathrm{P}(\mathrm{VDF}-\mathrm{TrFE})$ short chains, we have recovered much of the detail observed in the combined photoemission and inverse photoemission [25, 27]; such qualitative success has been noted with other polymers [27, 45, 62] and large adsorbed molecular systems [28$30,63]$. It is under the illumination of UV radiation that changes in the density of states are observed at the conduction band edge, shown in Figure 6.

As seen in Figure 6, the illumination of $337 \mathrm{~nm}(3.66 \mathrm{eV})$ light on the ferroelectric P(VDF-TrFE 70:30) thin films induces a small increase in the density of states at the conduction band edge. With UV irradiation the unoccupied density of states moves closer to the Fermi level as observed in inverse photoemission (Figure 6a). With the absorption of water, the increase in the unoccupied density of states near the Fermi level is even more pronounced in inverse photoemission (Figure 6b). We cannot yet conclusively assign the origin of the increase in the unoccupied density of states near the Fermi level due to UV irradiation. With about 1 photon per surface dipole per $4 \mathrm{~ns}$ pulse, in the geometry of our inverse photoemission experiment, the fact that any change is observed in the inverse photoemission spectra with illumination is quite surprising. The observation of a change in the density of states (however small), with illumination of the sample, strongly suggests the excitation of long-lived metastable states given that the UV laser source is both pulsed and has a relatively weak flux per unit area [25].

The fact that there is a greater increase in the unoccupied density of states near the Fermi level under UV illumination with absorbed water than without is consistent with a more facile local dipole reorientation in $\mathrm{P}(\mathrm{VDF}-\mathrm{TrFE}$ 70:30) when water is present, and very long-lived metastable states that involve dipole reorientation. Again, water absorption does create distortions of the $\mathrm{P}(\mathrm{VDF}-\mathrm{TrFE}$ 70:30) chains leading to a reduction of crystallinity $[19,20,22]$ and a distortion of the ferroelectric dipoles away from the surface normal in the immediate proximity to the water molecule [23]. This could also lower the activation barrier to dipole reversal (or just a significant dipole or multiple dipole reorientation) with electronic or dipole excitations. The long-lifetime suggests that multiple dipoles may "switch" with a single electron excitation, and this is consistent with steric hindrance (structural complexities) for single dipole reorientation.

\section{Dipole interactions or exciton decay?}

To illustrate further the difficulties in disentangling the possible interplay between dipole excitations and long-lived excitons in the ferroelectric polymer $\mathrm{P}(\mathrm{VDF}-\mathrm{TrFE} 70: 30)$, let us consider the bromoform adsorption on $\mathrm{P}(\mathrm{VDF}-\mathrm{TrFE}$ 70:30). Reversible bromoform adsorption on crystalline P(VDF-TrFE 70:30) is both associative and reversible [31]. Molecular bromoform adsorption appears to be an activated process at $120 \mathrm{~K}$ with enhanced adsorption following the initial adsorption of bromoform. Strong intermolecular interactions are also implicated in the presence of a weak shake off or screened photoemission final state, whose intensity scales with the unscreened photoemission final state [31], as seen in Figure 7.

With bromoform adsorption on $\mathrm{P}(\mathrm{VDF}-\mathrm{TrFE} 70: 30)$, the observed X-ray photoemission features of the bromine $3 \mathrm{~d}$ core level 


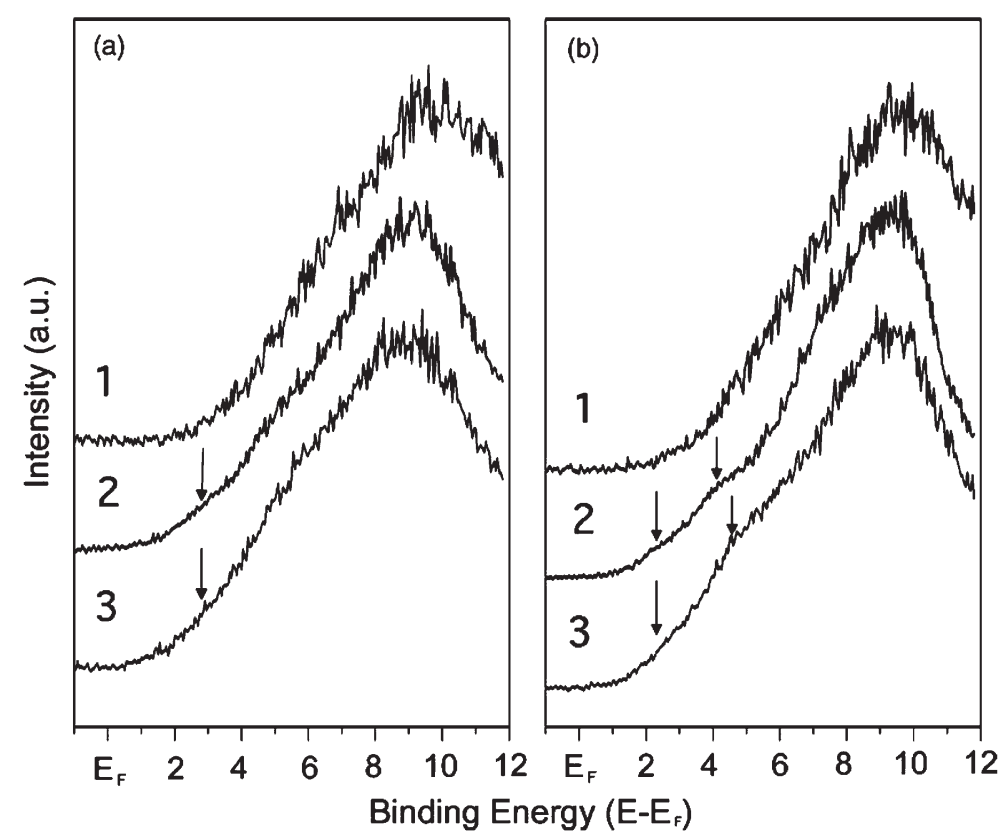

Figure 6. Inverse photoemission of clean $\mathrm{P}(\mathrm{VDF}-\mathrm{TrFE})$ (curve 1, in panel a) and with absorbed water (curve 1, in panel b). Inverse photoemission of the unoccupied states with the excitation of metastable states of clean P(VDF-TrFE) (a) and following 100 Langmuirs of water exposure at $190 \mathrm{~K}$ (b), undertaken with incident UV laser light $(337 \mathrm{~nm})$ polarized with E parallel with film surface (curves 2) and parallel with the surface normal (curves 3). The arrows in the figure indicate some of the regions of apparent additional unoccupied density of states occurring with simultaneous $\mathrm{UV}$ irradiation. Values are in eV. Adapted from [25].

are approximately at a binding energy of $72.1 \pm 0.1 \mathrm{eV}$ with low bromoform exposure and increase to $72.6 \pm 0.1 \mathrm{eV}$ with higher exposures at $120 \mathrm{~K}$ [31]. These bromine $3 \mathrm{~d}$ core level binding energy features are a signature of molecular bromoform [31, 32]. There is also a much smaller intensity feature at a $63 \mathrm{eV}$ binding energy, which is more difficult to assign.

A 9-10 eV chemical shift to smaller binding energies (72 eV reduced to about $63 \mathrm{eV}$ ) is difficult to associate with fragment formation on a polymer surface, or an absorbed fragment [31, 32], as this should lead to an increase in binding energy, not a decrease. The smaller bromine feature at $63 \mathrm{eV}$ binding energy has far too

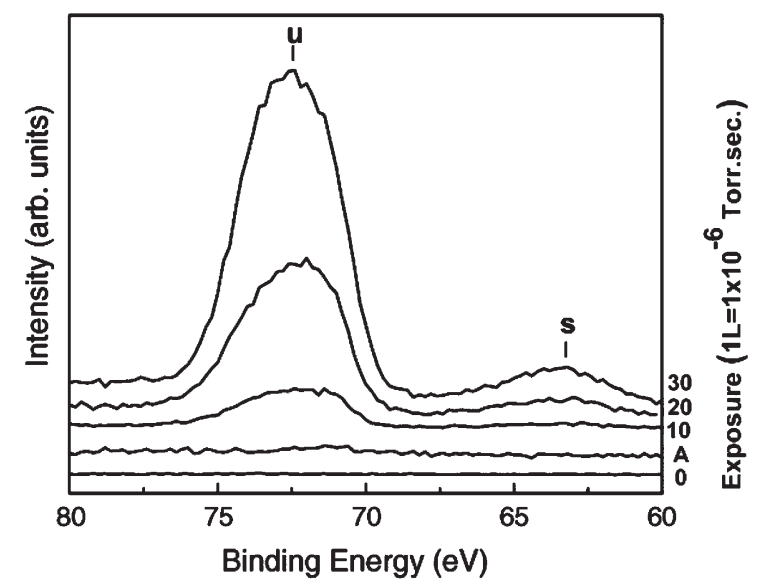

Figure 7. The sequence of X-ray photoemission spectra of a 5 monolayer thick $\mathrm{P}(\mathrm{VDF}-\mathrm{TrFE} 70: 30)$ film at $120 \mathrm{~K}$ film before and after $\mathrm{CHBr}_{3}$ exposure $(10,20$, and $30 \mathrm{~L})$. Bromine $3 \mathrm{~d}_{3 / 2}$ and $3 \mathrm{~d}_{5 / 2}$ are superposed around $73 \mathrm{eV}$ and the possible screened final state feature is seen at $63 \mathrm{eV}$ binding energy. Spectrum $\mathrm{A}$ is after annealing to room temperature showing that molecular adsorption of bromoform on $\mathrm{P}(\mathrm{VDF}-\mathrm{TrFE})$ is reversible. The screened $(\mathrm{s})$ and unscreened $(\mathrm{u})$ final states are indicated. small or too large a binding energy to be explained by the weak bromine Auger electron lines at $1203 \mathrm{eV}$ (roughly $51 \mathrm{eV}$ binding energy with $\mathrm{Mg} \mathrm{Ka}$ ) and $1167 \mathrm{eV}$ (roughly $87 \mathrm{eV}$ binding energy with $\mathrm{Mg} \mathrm{Ka}$ ) kinetic energies and is not present in the bromine $3 d$ XPS spectra of photo-dissociated bromoform [31, 32] or 1-bromo,4-iodobenzene [31]. The apparent $\mathrm{Br} 3 \mathrm{~d}$ core level feature, at $63 \mathrm{eV}$ binding energy, is unlikely to be the result of a bromine Auger electron emission line. This feature is also evident at about $63.5 \mathrm{eV}$ for very high coverages of bromoform adsorbed on graphite, at two different photon energies $1486.6 \mathrm{eV}\left(\mathrm{Al}_{\mathrm{ka}}\right)$ and $1253.6 \mathrm{eV}\left(\mathrm{Mg}_{\mathrm{ka}}\right)$ [31], suggesting that this is the result of bromoform, no bromine adsorption.

The observed bromoform associated core level photoemission feature at much lower binding energies than the expected $\mathrm{Br}$ $3 \mathrm{~d}$ cores (at $63 \mathrm{eV}$ binding energy) may well be a consequence of some combinations of different final state effects. Other explanations for this very low binding energy Br $3 d$ XPS feature, like a photoemission final state shake-up or two hole bound state feature, are fairly easy to exclude, as these phenomena also lead to apparent increases in the apparent core level binding energy, not a decrease in binding energy, as observed here.

The ratio of the $63 \mathrm{eV}$ satellite to the main bromine $3 \mathrm{~d}$ core photoemission feature is constant with coverage, for bromoform adsorbed on P(VDF-TrFE 70:30) [31]. This suggests one possibility for the $63 \mathrm{eV}$ bromine feature is a screened bromine $3 \mathrm{~d}$ photoemission final state for molecular bromoform, not present for photo-dissociated bromoform on $\mathrm{P}(\mathrm{VDF}-\mathrm{TrFE} 70: 30)$ [31]. Although $\mathrm{P}(\mathrm{VDF}-\mathrm{TrFE}$ 70:30) is an excellent dielectric (as is bromoform), the polymer substrate does have dipoles that can rotate, as we have now noted numerous times. A strong interaction between adsorbate species and the substrate could lead to charge transfer in the photoemission final state giving rise to a final state akin to the screened final state of molecular nitrogen or carbon monoxide on many metal substrates $[64,65]$. For both $\mathrm{CO}$ and $\mathrm{N}_{2}$, a very large difference in the XPS core level binding energies is observed between the screened and unscreened final states, as is observed for bromoform [31]. Unlike adsorbed $\mathrm{CO}$ and $\mathrm{N}_{2}$ on many metal substrates, for bromoform ad- 
sorption on $\mathrm{P}(\mathrm{VDF}-\mathrm{TrFE}$ 70:30) and graphite, it is the unscreened final state (higher binding energy) features that are favored, while for $\mathrm{CO}$ and $\mathrm{N}_{2}$, the screened final state is favored.

Dipole rotation leading to increased screening in the final state could occur from transient dipole rotation in both the ferroelectric $\mathrm{P}(\mathrm{VDF}-\mathrm{TrFE})$ substrate as well as by adjacent bromoform molecules [31], if there is sufficient intermolecular interaction. This dipole rotation in adjacent bromoform molecules, leading to increased photoemission final state screening might explain why this far smaller binding energy XPS feature is also seen for very high bromoform adsorption coverages on graphite [31], although weaker in intensity than observed for bromoform on P(VDF-TrFE 70:30). An interaction with the substrate and adjacent bromoform molecular dipoles could lead to very different final states if the dipoles reverse during the photoemission process [31]. Although photoemission is a relatively fast process with respect to single dipole reversal (about a nanosecond for $\mathrm{P}(\mathrm{VDF}-\mathrm{TrFE})$ ), a realignment of an adjacent dipole could bring more charge in close proximity to the bromoform ion final state leading to a more "screened" final state, and effectively decrease the binding energy. The energy difference between screened and unscreened finals states can be quite large [64], and indeed larger than many chemical shifts. While other intermolecular interactions between adsorbates could also lead to different final states, the large HOMO-LUMO gap suggests that such effects like charge transfer to unoccupied states is unlikely, although the large frontier orbitals of bromine would tend to enhance such interactions. The effects of electronic excitations which are seen with the just described photo-enhanced thermal desorption of water from P(VDF-TrFE 70:30) may be similar, but for absorbed water, the electronic excitations are associated with the $\mathrm{P}(\mathrm{VDF}-\mathrm{TrFE}$ 70:30) polymer substrate, not the adsorbate $[25,27]$ as may be the case with bromoform adsorption on P(VDF-TrFE 70:30).

The problem with this model of final state screening due to dipole rotation is that dipole rotation for $\mathrm{P}(\mathrm{VDF}-\mathrm{TrFE})$ as well as adjacent bromoform is slow compared to the photoemission process. In the case of adjacent bromoform screening the photoemission final states, there is no need for complete dipole reversal and realignment, as partial molecule reorientation of an adjacent molecule could have a profound effect. Bromoiodobenzene being far larger would have any rotation or molecular realignment more readily hindered by steric effects and thus might address why this weak core level feature at $9-10 \mathrm{eV}$ smaller binding energies is not observed at all with bromoiodobenzene and other larger bromine functionalized organics on non-ferroelectric substrates [31].

Another possible dipole excitation could be invoked to explain the $\mathrm{Br} 3 \mathrm{~d}$ photoemission feature. If there is a large population of long-lived exciton states in adsorbed bromoform, then collapse of the exciton during the photoemission process could impart that energy to the outgoing photoelectron. Given the size of the bromoform HOMO-LUMO gap, even when adsorbed on P(VDF-TrFE 70:30) (Figure 8), this explanation is consistent with the nearly $10 \mathrm{eV}$ additional kinetic energy needed for a $63 \mathrm{eV}$ binding energy $\mathrm{Br} 3 \mathrm{~d}$ satellite. The change in the density of states of P(VDF-TrFE 70:30) and the P(VDF-TrFE 70:30) with absorbed water, seen with UV irradiation as discussed in the previous section, is not seen here. This suggests that such excitons would be at least extrinsic to P(VDFTrFE 70:30). This surmise is at least consistent with the attribution of the observed changes in the density of states for P(VDF-TrFE 70:30) with the bromoform adsorption in photoemission and inverse photoemission (Figure 8) to molecular bromoform.

Following bromoform adsorption on P(VDF-TrFE 70:30) at $120 \mathrm{~K}$, there is a clear suppression of the $\mathrm{P}(\mathrm{VDF}-\mathrm{TrFE}$ 70:30) photoemission and inverse photoemission features, while features attributable to bromoform are added. Very evident in the inverse photoemission spectra is the suppression of the unoccupied density of states due to the lowest unoccupied molecular orbital contributions of $\mathrm{P}(\mathrm{VDF}-\mathrm{TrFE}$ 70:30) with increasing bromoform

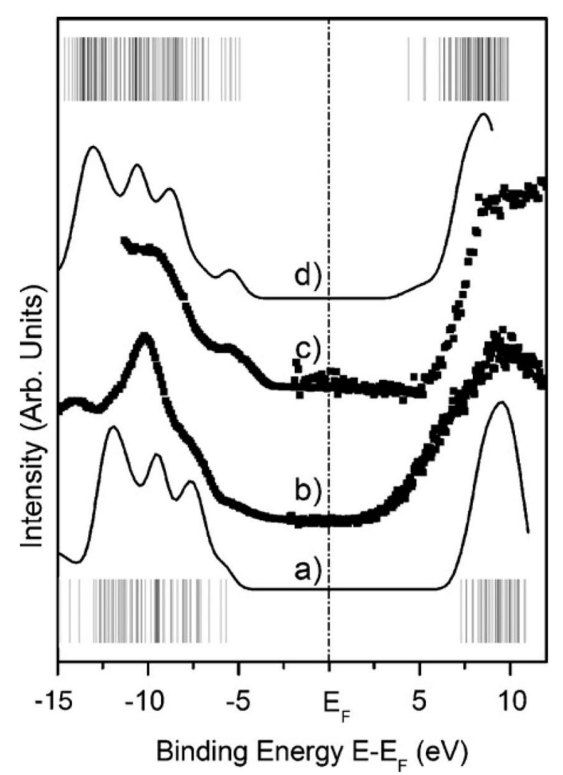

Figure 8. The comparison of (a) the model calculations of the density of states for P(VDF-TrFE) and (b) the combined photoemission (UPS) (left) and inverse photoemission (IPES) (right) experimental spectra for clean P(VDF-TrFE). Also shown is the comparison of (c) the combined UPS (left) and IPES (right) experimental spectra for $30 \mathrm{~L}$ of bromoform adsorbed on P(VDF-TrFE) film at $120 \mathrm{~K}$ to (d) the model single molecule density of states for bromoform. The molecular orbital eigen values are shown for $\mathrm{P}(\mathrm{VDF}-\mathrm{TrFE})$ at the bottom and for bromoform at the top. Adapted from [31].

coverages. The new features introduced by bromoform adsorption on $\mathrm{P}(\mathrm{VDF}-\mathrm{TrFE}$ 70:30) match the expected molecular orbitals of bromoform, as seen in Figure 8. This tends to suggest that bromoform adsorption does "wet" the surface of P(VDF-TrFE) [31]: the bromoform must cover the $\mathrm{P}(\mathrm{VDF}-\mathrm{TrFE})$ polymer surface. The features associated with $\mathrm{P}(\mathrm{VDF}-\mathrm{TrFE})$ are quickly suppressed with exposure, so that we can exclude an adlayer island like growth mode for bromoform on $\mathrm{P}(\mathrm{VDF}-\mathrm{TrFE})$ polymer surface.

Unlike water, where absorption initially dominates over adsorption on P(VDF-TrFE 70:30) [19-27], an absorbed phase of bromoform in P(VDF-TrFE 70:30) is not evident in photoemission. Bromoform absorption does not explain the approximately 9$10 \mathrm{eV}$ energy difference in the two possible Br 3d XPS core features (Figure 7), given this is also seen with bromoform adsorption on graphite [31]. In any case, a 9-10 eV shift between the two features, seen in the XPS spectra, is too large for a bromine chemical shift for largely associative absorption of bromoform on or in a dielectric polymer.

\section{Molecular orientation}

The factors that determine adsorbate molecular orientation are, in large measure, interplay and balance among competing forces that include the chemical interaction and the interface dipole. This is particularly true at a hetero-molecular interface. This is very evident in the differences between metal phthalocyanine (MPc; $\mathrm{M}=\mathrm{Cu}, \mathrm{Co})$ to PVDF heterojunction diodes.

The origin of the huge differences in band gap and molecular orbital position between $\mathrm{CuPc}$ on $\mathrm{Au}$ and $\mathrm{CuPc}$ on $\mathrm{P}(\mathrm{VDF}-\mathrm{TrFE}$ 70:30) indeed suggests that CuPc does not lie flat on P(VDF-TrFE 70:30) $[28,29]$ or short chain evaporated PVDF [30], as seen in Figure 9 and Figure 10, respectively. The low-lying CuPc unoccupied molecular orbitals, along with the highest occupied molecular orbitals have strong $\mathrm{Cu}$ and $\mathrm{N}$ weight. Therefore, molecules lying well 


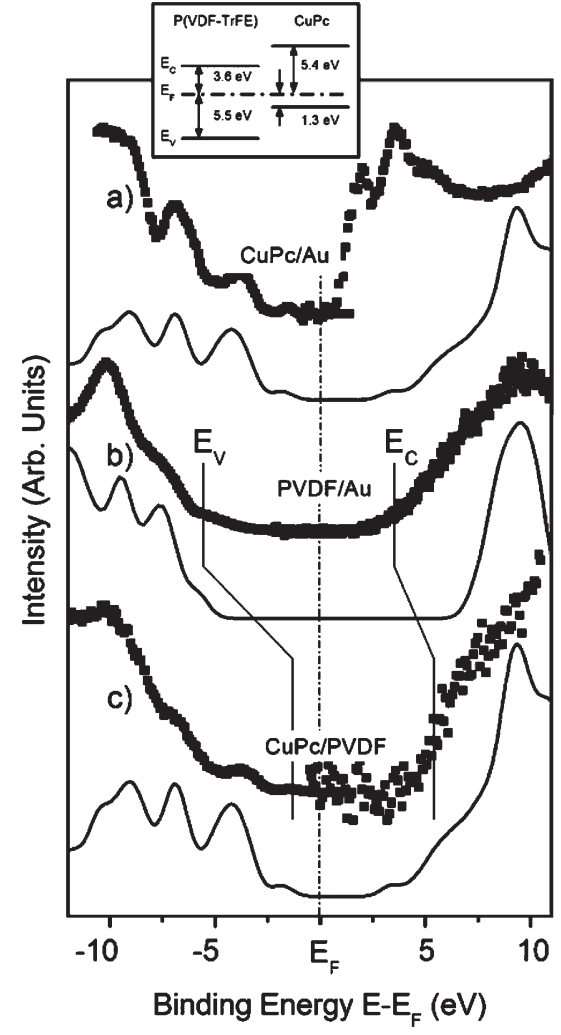

Figure 9. Photoemission (left) and inverse photoemission (right) spectra of poly(vinylidene fluoride with trifluoroethylene) $\mathrm{P}(\mathrm{VDF}-\mathrm{TrFE})$ on $\mathrm{Au}(\mathrm{b})$ and $\mathrm{CuPc}$ adsorbed on $\mathrm{Au}(\mathrm{a})$ and on the crystalline ferroelectric $\mathrm{P}(\mathrm{VDF}-\mathrm{TrFE})$ (c). For comparison, the ground state density of states is shown, as derived from semiempirical single molecule calculations (PM3) with a $1 \mathrm{eV}$ Gaussian width added to the eigen values, with no correction for final state or matrix element effects (thin line curves). The relative shifts in the edges of valence band and conduction band are indicated by vertical bars for PVDF on Au and CuPc on PVDF. The corresponding energy levels of these components are schematically shown in the inset, to indicate the relative band offsets of the two molecular systems, in the pertinent heterojunction. Adapted from [28].

out of the plane of the surface are expected to have molecular orbitals with strong $\mathrm{Cu}$ and $\mathrm{N}$ weight suppressed in a highly surface sensitive spectroscopy like inverse photoemission while molecular orbitals with stronger ligand weight would not be so strongly suppressed, as observed in Figure 9 and Figure 10. This is consistent with the fact that $\mathrm{CuPc}$ tends to lie flat on metal substrates and stand on oxide and insulator surfaces [66]. Overall, the effects of final state screening as well as molecular orientation can both significantly affect the unoccupied states of adsorbed metal phthalocyanines ( $\mathrm{MPc} ; \mathrm{M}=\mathrm{Cu}, \mathrm{Ni}, \mathrm{Co}$ ), as noted below and elsewhere [30].

Strong intermolecular and substrate interactions and final state screening of the metal phthalocyanines on $\mathrm{Au}(111)$ [28] are believed to decrease the size of the HOMO-LUMO gap inferred from combined photoemission and inverse photoemission spectra $[28,67]$. There is clearly an increase in the HOMO-LUMO gap, as observed for CuPc on P(VDF-TrFE) (Figure 9), and CuPc on PVDF (Figure 10) compared to that of $\mathrm{CuPc}$ on $\mathrm{Au}(111)$ [28-30]. This increased HOMO-LUMO gap and the similarity of the HOMOLUMO gap and the density of states for CuPc adsorbed on these organic ferroelectrics with the semiempirical PM3 theory (Figure 9) suggest that the electronic structure of CuPc on PVDF-TrFE or PVDF more closely resembles that of an isolated molecule, not the fully screened gap of an adsorbed molecule on a metal substrate.

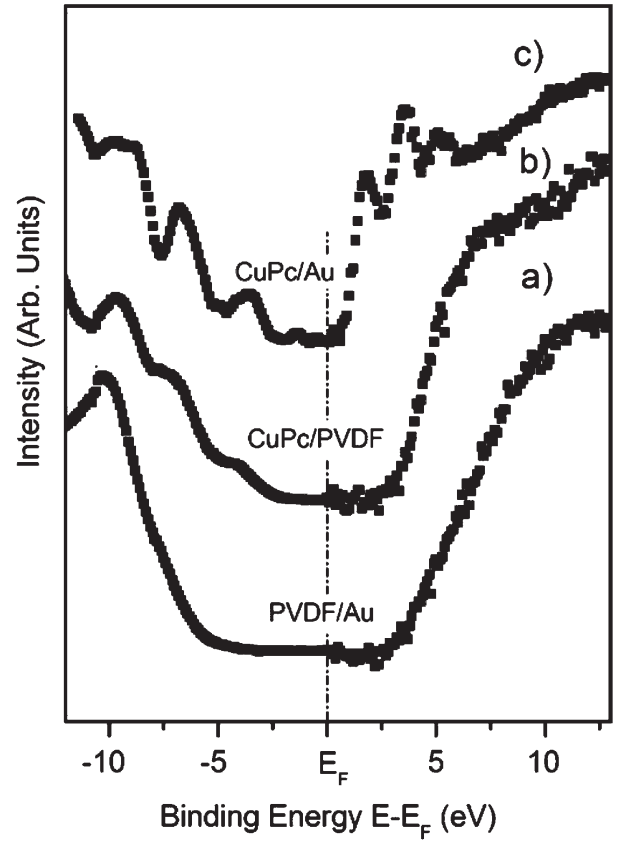

Figure 10. Photoemission (left) and inverse photoemission (right) spectra of short chain evaporated poly(vinylidene fluoride) PVDF on $\mathrm{Au}$ (a) and $\mathrm{CuPc}$ adsorbed on $\mathrm{Au}$ (c) and on short chain evaporated PVDF (b). Adapted from [30].

While CuPc does not lie "flat" but rather adopts some upright configuration on PVDF, it might well be argued that evaporated PVDF is either a "technical surface" (like indium oxide, oxidized silicon or a sputtered metal thin film) or a good insulator [66]. The local possible roughness of the short chain evaporated PVDF surface does not apply to the Langmuir-Blodgett grown P(VDF-TrFE 70:30) surface, so the observed canted or upright bonding configuration for CuPc on the $\mathrm{P}(\mathrm{VDF}-\mathrm{TrFE} 70: 30)$ surface $[28,29]$ argues for an affect on molecular orientation that is due to something other than surface roughness. What is common to both polymer substrates is that both are insulators with no free electrons. In this picture of reduced interaction with the substrate, a canted or upright orientation for the adsorbed CuPc is expected [28, 29]. With reduced interaction with a non-conducting polymer dielectric substrate, the simple view would be that CoPc should not exhibit a significantly different absorption behavior from other adsorbed metal (II) phthalocyanines, in terms of either orientation or interaction. What is surprising is that CoPc does adopt a bonding configuration that appears, in the combined photoemission and inverse photoemission, to be largely planar with both the $\mathrm{Au}(111)$ and PVDF surfaces. The observations for CoPc on PVDF [30] indicate that the details of the metal phthalocyanine ( $\mathrm{MPc} ; \mathrm{M}=\mathrm{Cu}$, $\mathrm{Ni}, \mathrm{Co}$ ) interactions with an insulating substrate can play a bigger role than expected, overcoming the influence of local roughness and substrate screening (absence of substrate conductivity).

$\mathrm{CoPc}$ exhibits far stronger interactions or charge transfer to $\mathrm{Au}(111)$ [53, 67] and $\mathrm{Au}(100)$ [68]. Such stronger interactions must be invoked to explain the planar molecular orientation on PVDF that results in such a significant difference in the apparent electronic structure of CoPc on PVDF (Figure 11) compared to CuPc on P(VDF-TrFE 70:30) (Figure 9) and PVDF (Figure 10) [30].

Gold is a good conductor, while PVDF is a good dielectric, thus strong interactions must be invoked to overcome the natural tendencies $[29,66]$ of CoPc to lie canted or tilted well out of the plane of the surface on PVDF. The differences between a conducting and non-conducting substrate can be compared for $\mathrm{CoPc}$, as the orientation on both substrates appears to be similar, even for some- 


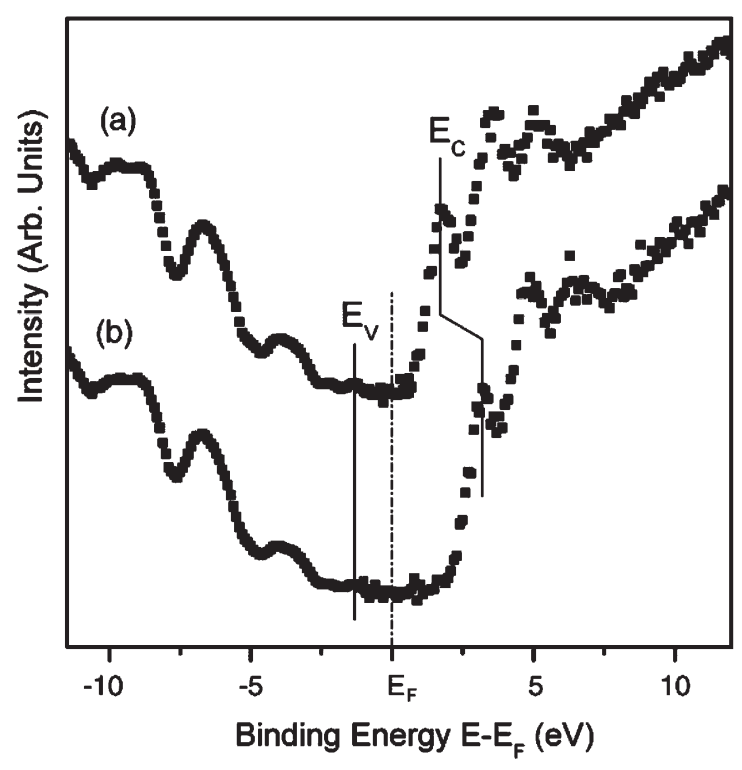

Figure 11. The photoemission (left) and inverse photoemission (right) spectra of molecular multilayer CoPc films adsorbed on (a) $\mathrm{Au}(111)$ and (b) PVDF substrates at room temperature. Binding energies are in terms of $E-E_{F}$. Adapted from [30].

what thicker (several molecular monolayer) CoPc films, as seen in Figure 11. While the same photoemission and inverse photoemission features, due to the CoPc molecular orbitals, are evident for CoPc on both $\mathrm{Au}(111)$ and PVDF, there are clear differences [30]. There is a decrease in the size of the HOMO-LUMO gap for CoPc

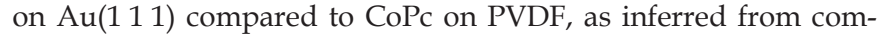
bined photoemission and inverse photoemission spectra in Figure 11. An increase in the HOMO-LUMO gap, as observed for CoPc on PVDF, suggests less screening by the PVDF substrate than is the case for the Au substrate [30]. Because PVDF is not only a ferroelectric but also a dielectric [35, 40], a larger HOMO-LUMO gap is expected [30]. For CoPc on both PVDF and $\mathrm{Au}(111)$, the HOMO-LUMO gap still remains much smaller than expected of an isolated molecule, indicative of substrate interactions that close the HOMO-LUMO gap.

\section{The hetero-molecular interface dipole}

At the hetero-molecular interface, the molecular band offsets can be modified by changing the dipole orientation at the intermolecular interface. The combined photoemission and inverse photoemission studies, just discussed, reveal the changes in electronic structure due to changes in molecular orientation and substrate interaction. These changes in electronic structure have further significance: in heterojunction diode structure based on a hetero-molecular interface, the diode exhibits conduction properties that are altered in response to changes to the molecular band offsets. As a demonstration, thin film $\mathrm{CuPc}$ to crystalline ferroelectric copolymer poly(vinylidene fluoride with trifluoroethylene) heterojunction diodes, without additional dopants, show hysteretic behavior. While doping is a (more) conventional method for shifting the molecular orbital band offsets with respect to the Fermi level [69], changing molecular orbital alignment can be undertaken in other ways $[28,29]$. One approach is to change the interface dipole alignment. This has been demonstrated for thin film copper phthalocyanine $(\mathrm{CuPc})$ to crystalline ferroelectric $\mathrm{P}(\mathrm{VDF}-\mathrm{TrFE} 70: 30)$ heterojunction diodes $[28,29]$.

Although we cannot ascertain the majority carrier for CuPc thin films from electron spectroscopies alone (i.e. is it $n$-type or $p$-type?), the band alignment for CuPc on $\mathrm{P}(\mathrm{VDF}-\mathrm{TrFE})$ suggests that a het-

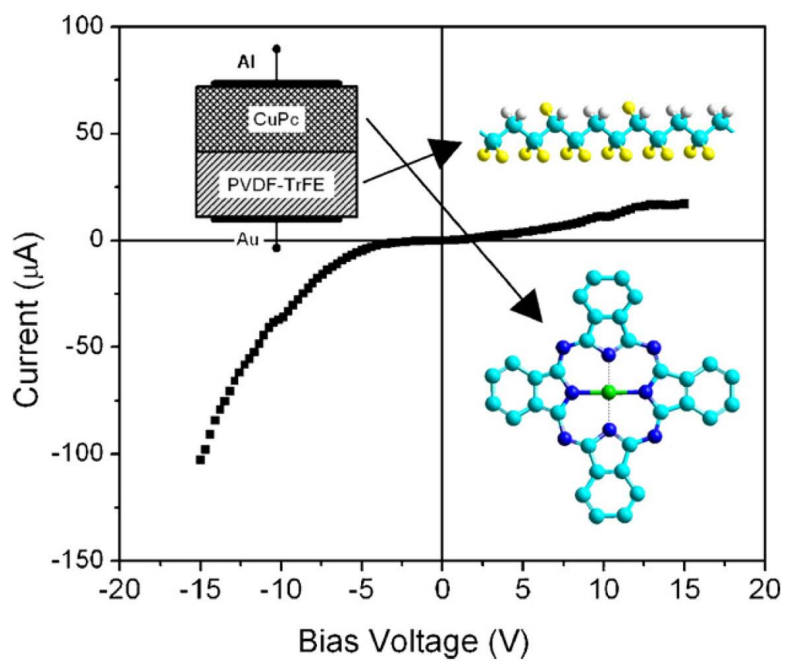

Figure 12. $I-V$ characteristics of diodes fabricated from $4 \mathrm{~nm}$ of $\mathrm{CuPc}$ deposited on $3 \mathrm{~nm}$ of $\mathrm{P}(\mathrm{VDF}-\mathrm{TrFE})$, as indicated by the inset schematic structure. Schematic representations are also shown for P(VDF$\mathrm{TrFE}$ ) (upper right) and CuPc (lower right), with carbon (blue), fluorine (yellow), nitrogen (navy blue), and copper (green) indicated. For $\mathrm{CuPc}$, the hydrogen has been left off to simplify the schematic. Adapted from [28, 29].

erojunction diode can be fabricated with P(VDF-TrFE 70:30), as illustrated in Figure 12. Similar heterojunction diode fabrication has been demonstrated for polyaniline and P(VDF-TrFE 70:30) [29, 70], as well. Indications of dipole interaction between $4 \mathrm{~nm}$ thick $\mathrm{CuPc}$ films and 3-4 nm thick films of the ferroelectric material P(VDFTrFE 70:30) are evident in the electric field controlled $p-n$ diode formed by combining these two molecular thin films together. By biasing the diode by $+15 \mathrm{~V}$ to ensure dipole reversal in the ferroelectric polymer substrate, hysteresis is seen in the current versus voltage traces at low bias, as seen in Figure 13. Application of bias voltages up to $\pm 15 \mathrm{~V}$ is more than sufficient to polarize the ferroelectric $\mathrm{P}(\mathrm{VDF}-\mathrm{TrFE} 70: 30)[35,39,40]$, and/or flip the dipole direction of $\mathrm{P}(\mathrm{VDF}-\mathrm{TrFE})$ (or both P(VDF-TrFE 70:30) and CuPc) thin films of this thickness, so this is not entirely unexpected [28, 29].

The dipole interaction could affect the diode properties in several ways. The local electric field due to the $\mathrm{P}(\mathrm{VDF}-\mathrm{TrFE})$

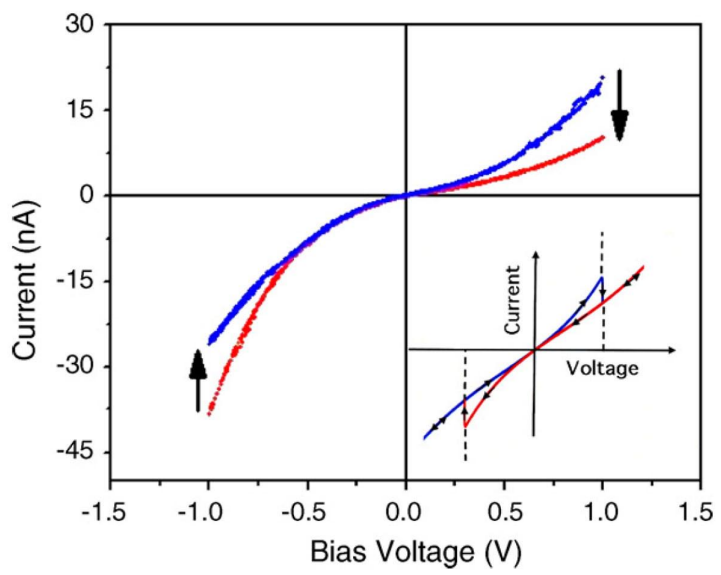

Figure 13. Reproducible current differences in the $I-V$ curves are seen at small bias (shown here) after applying larger voltages to ensure ferroelectric substrate dipole reversal from -15 to $+15 \mathrm{~V}$ (blue) and +15 to $-15 \mathrm{~V}$ (red) in heterojunctions formed from $4 \mathrm{~nm}$ of CuPc deposited on $3 \mathrm{~nm}$ of $\mathrm{P}(\mathrm{VDF}-\mathrm{TrFE})$. A schematic of the expectation $[75,78]$ for a ferroelectric tunnel junction barrier are indicated in the inset as adapted from [75]. Adapted from [28, 29]. 


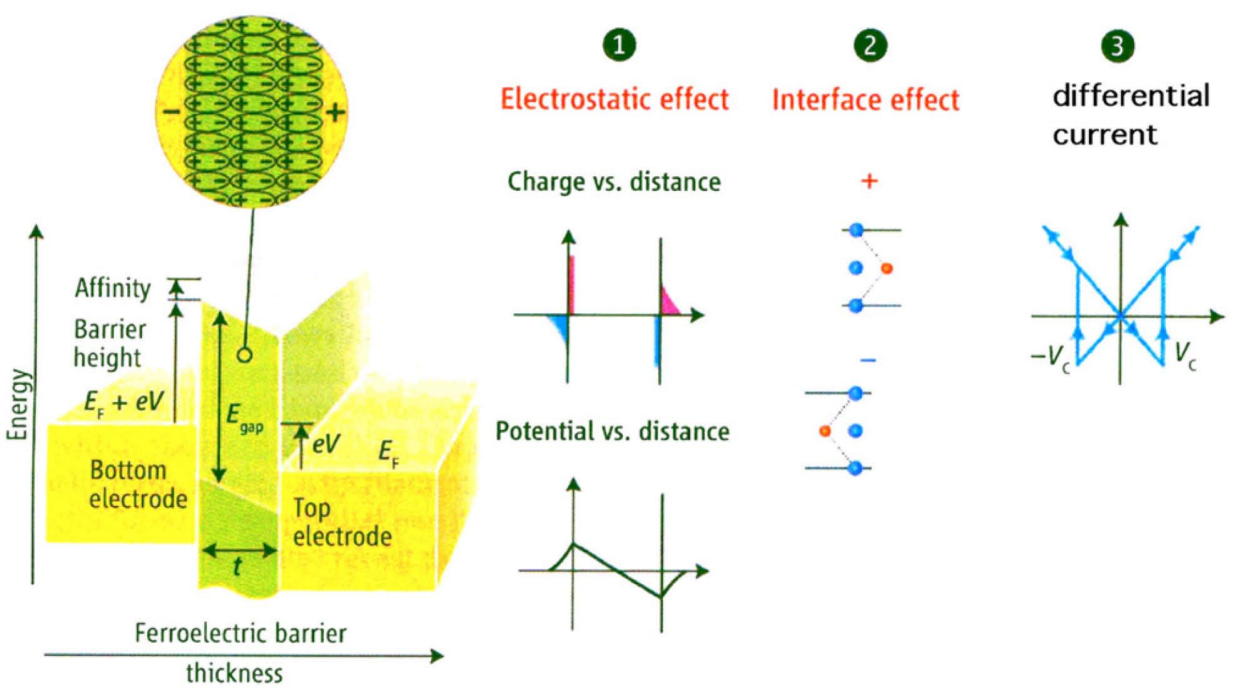

Figure 14. Mechanisms affecting tunneling in ferroelectric tunnel junctions: (1) electrostatic potential at the interface, (2) interface bonding, and (3) the differential current. Adapted from Ref. [72], reproduced with permission.

could align the CuPc's dipoles and either change the molecular orientation(s) or change the molecular dipole alignment(s) at the interface, as is suggested by the difference in $\mathrm{CuPc}$ and $\mathrm{CoPc}$ bonding on PVDF [30]. A change in molecular orientation of $\mathrm{CuPc}$ in the PVDF/CuPc heterojunction could lead to a decrease or increase in the barriers to current [28, 29]. Changes in the barrier height can have dramatic changes in the tunneling current, and thus the changes could be due to behavior resembling a ferroelectric tunnel junction.

Given the fact that both the P(VDF-TrFE 70:30) and CuPc layers can be made very thin [28-30], it is also possible that these heterojunctions of Figure 12 and Figure 13 act also as ferroelectric tunnel junctions $[28,29,71]$. In ferroelectric tunnel junctions, the thin dielectric barrier layer is a ferroelectric. In such tunnel junction structures the screening of polarization charges is incomplete and consequently there is a non-vanishing depolarizing field inside the ferroelectric [71-73], as schematically illustrated in Figure 14. For ferroelectric tunnel junctions with asymmetric electrodes, as is the case here with $\mathrm{Au}$ on one side and $\mathrm{CuPc}$ on the other side, the electrostatic potential associated with the depolarizing field is different depending on the direction of the electric polarization [71-73].

Expectations on what should be the behavior of a ferroelectric tunnel junction barrier, based on the Brickman model [74], have been much discussed [71, 72, 73, 75, 76, 77, 78], and these expectations are borne out in the $\mathrm{P}(\mathrm{VDF}-\mathrm{TrFE}$ 70:30)-CuPc heterojunction device, as indicated in Figure 13. Definitive proof that this is in fact a ferroelectric tunnel junction does require further effort however.

\section{Implications for the future}

Organic heterojunction diodes [28, 29, 70, 79-81] and transistors [82-94] have been fabricated with the crystalline ferroelectric $\mathrm{P}(\mathrm{VDF}-\mathrm{TrFE})$. As the copolymer poly(vinylidene fluoride with trifluoroethylene) is ferroelectric, transistors, both fully organic heterojunctions [82-94] and hybrid heterojunctions with an inorganic semiconductor [95-99], exhibit gate voltage dependent hysteresis, indicating the potential of $\mathrm{P}(\mathrm{VDF}-\mathrm{TrFE})$ copolymers for nonvolatile random access memory devices. An example of this type of gate voltage dependent hysteresis for an organic heterojunction transistor fabricated with polyaniline as a $p$-layer $[69,70]$ on top of $\mathrm{P}(\mathrm{VDF}-\mathrm{TrFE} 70: 30)$ where the latter is the gate dielectric layer is illustrated in Figure 15. (The recipe for the polymeric heterostructure, that is the basis for this transistor, follows that given elsewhere [70].) Evidence for interface dipole coupling, however, is better illustrated in the diode geometry, as we have demonstrated already [28, 29].

Changing the dipole orientation may not only affect the MPc interaction at the PVDF interface, but may in fact lead to different molecular orientations for the various metal phthalocyanines as well as different molecular orbital alignments, as we have suggested here. The combination of these two effects may have broader impact in molecular heterojunction geometry. By combining a planar ferromagnetic metal organic species with a molecular ferroelectric like PVDF, it may be possible to construct a magneto-electric material, where an applied electric field $E$ results in the induction net magnetization $M$ [100]. This linear magnetoelectric effect, $M_{i}=a_{i j} E_{i}$, is governed by an induction constant $\left(a_{i j}\right)$ that is very, very small (on the scale of $\mathrm{ps} / \mathrm{m}$ ) for most inorganic magneto-electrics, and might be significantly larger for a suitable combination of organic layers. By developing a much better understanding of electric dipole and spin polarization at polymer

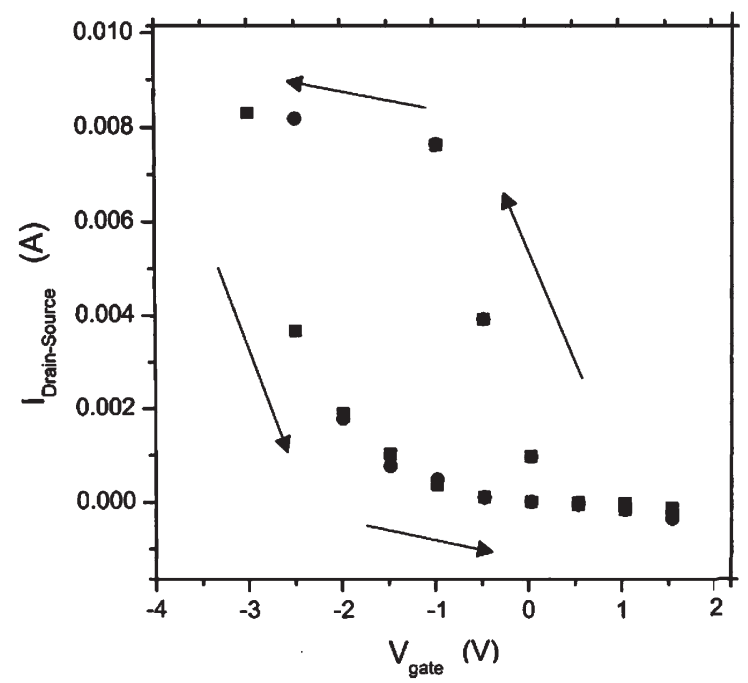

Figure 15. Source to drain currents plotted as a function of gate voltage for a heterojunction transistor fabricated with polyaniline as a $p$-layer (of thickness less than $100 \mathrm{~nm}$ ) on top of P(VDF-TrFE 70:30) where the latter is the gate dielectric layer of thickness less than $10 \mathrm{~nm}$. The source to drain bias is $0.2 \mathrm{~V}$, and hysteresis is evident. Arrows indicate the direction of the gate voltage as it is swept from +4 to $-4 \mathrm{~V}$. 
interfaces with select organometallic compounds, it may be possible to design magneto-electric devices [101, 102] with larger induction constants $\left(a_{i j}\right)$ as both molecular orientation and the concomitant magnetic coupling may be significantly altered. In the planar geometry or not, it seems clear that the metal phthalocyanines can be used to make rectifying molecular heterojunctions with PVDF, as in $[28,29]$, and illustrated in Figure 12.

\section{Acknowledgments}

The junior authors would like to acknowledge the seminal role played by research and textbooks by William Salaneck and colleagues in their scientific training. The authors would also like to acknowledge valuable conversations with K. Seki and M. Grunze in the summer of 2007 leading to the formulation of some of this research. The group of Jiandi Zhang contributed to the STM studies and the authors thank Stephen Ducharme for his technical assistance. This research was supported by the National Science Foundation through grant number CHE-0415421 and CHE-0650453.

\section{References}

[1] L.J. Whitman, C.E. Bartosch, W. Ho, G. Strasser and M. Grunze, Phys. Rev. Lett. 56 (1986), pp. 1984-1987.

[2] L.J. Whitman, C.E. Bartosch and W. Ho, J. Chem. Phys. 85 (1986), p. 3688.

[3] G. Ertl, S.B. Lee and M. Weiss, Surf. Sci. 114 (1982), pp. 527-545.

[4] M. Kiskinova and D.W. Goodman, Surf. Sci. 108 (1981), pp. 64-76.

[5] P.A. Dowben, A. Miller, H.-J. Ruppender and M. Grunze, Surf. Sci. 193 (1988), p. 336.

[6] J.K. Nørskov, S. Holloway and N.D. Lang, Surf. Sci. 137 (1984), p. 65.

[7] A.L. Cabrera, G. Tarrach, P. Lagos and G.B. Cabrera, Ferroelectrics 281 (2002), p. 53.

[8] E. Ramos-Moore, J.A. Baier-Saip and A.L. Cabrera, Surf. Sci. 600 (2006), p. 3472.

[9] A.L. Cabrera, F. Vargas, R.A. Zarate, G.B. Cabrera and J. EspinosaGangas, J. Phys. Chem. Solids 62 (2001), p. 927.

[10] R.F. Goncalves, N.L.V. Carreno, M.T. Escote, K.P. Lopes, A. Valentini, E.R. Leite, E. Longo and M.A. Machado, Quimica Nova 27 (2004), p. 862.

[11] J.L. Giocondi and G.S. Rohrer, Chem. Mater. 13 (2001), p. 241.

[12] Y. Yun, L. Kampschulte, M. Li, D. Liao and E.I. Altman, J. Phys. Chem. C 111 (2007), p. 13951.

[13] Y. Yang, I. Eric and Altman, J. Am. Chem. Soc. 129 (2007), p. 15684.

[14] D. Li, M.H. Zhao, J. Garra, A.M. Kolpak, A.M. Rappe, D.A. Bonnell and J.M. Vohs, Nat. Mater. 7 (2008), p. 473.

[15] A.S. Castela and A.M. Simões, Corros. Sci. 45 (2003), p. 1647.

[16] N.L. Levshin and S.G. Yudin, Polym. Sci. B 46 (2004), pp. 348-351.

N.L. Levshin and S.G. Yudin, Polym. Sci. B 46 (11) (2004), pp. 19811984 (translated from Vysokomolekulyaniye Svedineniya Ser. B).

[17] N.L. Levshin, S.G. Yudin and A.P. Diankina, Moscow Univ. Phys. Bull. 52 (1997), pp. 71-74 (translated from Vestnik Moskovskogo Universiteta Fizika UDC 541. 183.03).

[18] N.L. Levshin and S.G. Yudin, Moscow Univ. Phys. Bull. 54 (1999), p. 34.

[19] P.A. Jacobson, L.G. Rosa, C.M. Othon, K. Kraemer, A.V. Sorokin, S. Ducharme and P.A. Dowben, Appl. Phys. Lett. 84 (2004), p. 88.

[20] L.G. Rosa, P.A. Jacobson, R. Lemoine and P.A. Dowben, J. Appl. Cryst. 37 (2004), p. 672.
[21] P.A. Jacobson, L.G. Rosa, K. Kraemer, S. Ducharme and P.A. Dowben, Mater. Lett. 61 (2007), p. 1137.

[22] L.G. Rosa, P.A. Jacobson and P.A. Dowben, J. Phys. Chem. B 109 (2005), p. 532.

[23] L.G. Rosa, I.N. Yakovkin and P.A. Dowben, J. Phys. Chem. B 109 (2005), p. 14189.

[24] L.G. Rosa, J. Xiao, Y.B. Losovyj, Y. Gao, I.N. Yakovkin, X.C. Zeng and P.A. Dowben, J. Am. Chem. Soc. 127 (2005), p. 17261.

[25] L.G. Rosa, P.A. Jacobson and P.A. Dowben, J. Phys. Chem. B 110 (2006), p. 7944.

[26] C.C. Ilie, P.A. Jacobson, M. Poulsen, L.G. Rosa, D.S. Reddy, J.M. Takacs, S. Ducharme and P.A. Dowben, Responsive soft matterchemistry and physics for assemblages, films and forms 0947A03-01. In: R.A. Vaia, J. Genzer, G.H. McKinley and N. Tabiryan, Editors, MRS Symposium Proceedings 947E (2007).

[27] P.A. Dowben, L.G. Rosa and C.C. Ilie, Z. Physikalische Chemie 222 (2008), p. 755.

[28] J. Xiao, A. Sokolov and P.A. Dowben, Appl. Phys. Lett. 90 (2007), p. 242907.

[29] P.A. Dowben, J. Xiao, B. Xu, A. Sokolov and B. Doudin, Appl. Surf. Sci. 254 (2008), pp. 4238-4244.

[30] J. Xiao and P.A. Dowben, J. Mater. Chem. 19 (2009), p. 2172.

[31] J. Xiao, C.C. Ilie, N. Wu, K. Fukutani and P.A. Dowben, Surf. Sci. 603 (2009), p. 513.

[32] C.C. Ilie, J. Xiao, P.A. Dowben, Polymer-based smart materialsprocess, properties and applications, In: Z. Cheng, Q. Zhang, S. Bauer, D.A. Wrobleski, MRS Symposium Proceedings 1134, (2009) BB01-06.

[33] H. Qu, W. Yao, T. Garcia, J. Zhang, A.V. Sorokin, S. Ducharme, P.A. Dowben and V.M. Fridkin, Appl. Phys. Lett. 82 (2003), p. 4322.

[34] L. Cai, H. Qu, C. Lu, S. Ducharme, P.A. Dowben and J. Zhang, Phys. Rev. B 70 (2004), p. 155411.

[35] L.M. Blinov, V.M. Fridkin, S.P. Palto, A.V. Bune, P.A. Dowben and S. Ducharme, Uspekhi Fizicheskikh Nauk 170 (2000), pp. 247262 (Russian edition vol.).

L.M. Blinov, V.M. Fridkin, S.P. Palto, A.V. Bune, P.A. Dowben and S. Ducharme, Physics Uspekhi 43 (2000), pp. 243-257 (English edition volume).

[36] J. Choi, P.A. Dowben, S. Ducharme, V.M. Fridkin, S.P. Palto, N. Petukhova and S.G. Yudin, Phys. Lett. A 249 (1998), p. 505.

[37] J. Choi, C.N. Borca, P.A. Dowben, A. Bune, M. Poulsen, S. Pebley, S. Adenwalla, S. Ducharme, L. Robertson, V.M. Fridkin, S.P. Palto, N. Petukhova and A.V. Sorokin, Phys. Rev. B 61 (2000), p. 5760.

[38] C.N. Borca, S. Adenwalla, J. Choi, P.T. Sprunger, S. Ducharme, L. Robertson, S.P. Palto, J. Liu, M. Poulsen, V.M. Fridkin, H. You and P.A. Dowben, Phys. Rev. Lett. 83 (1999), p. 4562.

[39] A.V. Bune, V.M. Fridkin, S. Ducharme, L.M. Blinov, S.P. Palto, A.V. Sorokin, S. Yudin and A. Zlatkin, Nature 391 (1998), p. 874.

[40] S. Ducharme, S.P. Palto and V.M. Fridkin, Handbook of Slectric Films vol. 3, Academic Press (2002) pp. 546-592.

[41] J. Choi, P.A. Dowben, S. Pebley, A. Bune, S. Ducharme, V.M. Fridkin, S.P. Palto and N. Petukhova, Phys. Rev. Lett. 80 (1980), p. 1328 .

[42] S. Palto, L. Blinov, E. Dubovik, V. Fridkin, N. Petukhova, A. Sorokin, K. Verkhovskaya, S. Yudin and A. Zlatkin, Europhys. Lett. 34 (1996), p. 465.

[43] J. Choi, S.-J. Tang, P.T. Sprunger, P.A. Dowben, V.M. Fridkin, A.V. Sorokin, S.P. Palto, N. Petukhova and S.G. Yudin, J. Phys. Condens. Matter 12 (2000), p. 4735.

[44] L.G. Rosa, Y.B. Losovyj, J. Choi and P.A. Dowben, J. Phys. Chem. B 109 (2005), p. 7817. 
[45] J. Xiao, L.G. Rosa, M. Poulsen, D.-Q. Feng, D.S. Reddy, J.M. Takacs, L. Cai, J. Zhang, S. Ducharme and P.A. Dowben, J. Phys. Condens. Matter 18 (2006), p. L155.

[46] L. Cai, X. Wang, Y. Darici, P.A. Dowben and J. Zhang, J. Chem. Phys. 126 (2007), p. 124908.

[47] Y. Losovyj, K. Morris, L. Rosa, J.D. Scott and P. Dowben, Nucl. Instrumen. Methods Phys. Res. A 582 (2007), p. 258.

[48] J. Choi, E. Morikawa, S. Ducharme and P.A. Dowben, Mater. Lett. 59 (2005), p. 3599.

[49] C.C. Ilie, P.A. Jacobson, I.N. Yakovkin, L.G. Rosa, M. Poulsen, D.S. Reddy, J.M. Takacs and P.A. Dowben, J. Phys. Chem. B 111 (2007), p. 7742 .

[50] P.A. Jacobson, C.C. Ilie, I.N. Yakovkin, M. Poulsen, D.S. Reddy, J.M. Takacs and P.A. Dowben, J. Phys. Chem. B 110 (2006), p. 15389.

[51] Y.B. Losovyj, I. Ketsman, E. Morikawa, Z. Wang, J. Tang and P.A. Dowben, Nucl. Instrumen. Methods Phys. Res. A 582 (2007), p. 264.

[52] J. Hormes, J.D. Scott and V.P. Suller, Synchrotron Radiat. News 19 (2006), p. 27.

[53] J. Xiao and P.A. Dowben, J. Phys. Cond. Matter 21 (2009), p. 052001.

[54] G. Comsa, R. David and K.D. Rendulic, Phys. Rev. Lett. 38 (1977), p. 775.

[55] H.P. Steinrück, A. Winkler and K.D. Rendulic, J. Phys. C: Solid State Phys. 17 (1984), p. L311.

[56] H.P. Steinrück, M. Luger, A. Winkler and K.D. Rendulic, Phys. Rev. B 32 (1985), p. 5032.

[57] N.A. Besley, J. Chem. Phys. 122 (2005), p. 184706.

[58] D. Charkarov and B. Kasemo, Phys. Rev. Lett. 81 (1998), p. 5181.

[59] M. Bai, A.V. Sorokin, D.W. Thompson, M. Poulsen, S. Ducharme, C.M. Herzinger, S. Palto, V.M. Fridkin, S.G. Yudin, V.E. Savchenko and L.K. Gribova, J. Appl. Phys. 95 (2004), p. 3372.

[60] K. Kobayashi, J. Phys. Chem. 87 (1983), p. 4317.

[61] C.-S. Tsai, J.-K. Wang, R.T. Skodje and J.-C. Lin, J. Am. Chem. Soc. 127 (2005), p. 10788.

[62] J. Xiao, M. Poulsen, D.S. Reddy, J.M. Takacs, Y.B. Losovyj and P.A. Dowben, Polym. Eng. Sci. 48 (2008), p. 1649.

[63] J. Liu, J. Xiao, S.-B. Choi, P. Jeppson, L. Jarabek, Y.B. Losovyj, A.N. Caruso and P.A. Dowben, J. Phys. Chem. B 110 (2006), pp. 26180-26184.

[64] C.R. Brundle, P.S. Bagus, D. Menzel and K. Hermann, Phys. Rev. B 24 (1981), p. 7041.

[65] E. Umbach, Solid State Commun. 51 (1984), p. 365.

[66] H. Peisert, T. Schwieger, J.M. Auerhammer, M. Knupfer, M.S. Golden, J. Fink, P.R. Bressler and M. Mast, J. Appl. Phys. 90 (2001), p. 466.

[67] X. Lu, K.W. Hipps, X.D. Wang and M. Ursula, J. Am. Chem. Soc. 118 (1996), p. 7197.

[68] T.S. Ellis, K.T. Park, M.D. Ulrich, S.L. Hulbert and J.E. Rowe, J. Appl. Phys. 100 (2006), p. 093515.

[69] B. Xu, J. Choi, A.N. Caruso and P.A. Dowben, Appl. Phys. Lett. 80 (2002), p. 4342.

[70] B. Xu, Y. Ovchenkov, M. Bai, A.N. Caruso, A.V. Sorokin, S. Ducharme, B. Doudin and P.A. Dowben, Appl. Phys. Lett. 81 (2002), p. 4281.

[71] J.P. Velev, P.A. Dowben, E.Y. Tsymbal, S.J. Jenkins and A.N. Caruso, Surf. Sci. Reports 63 (2008), p. 400.

[72] E.Y. Tsymbal and H. Kohlstedt, Science 313 (2006), p. 181.

[73] M.Y. Zhuravlev, R.F. Sabirianov, S.S. Jaswal and E.Y. Tsymbal, Phys. Rev. Lett. 94 (2005), p. 246802.
[74] W.F. Brinkman, R.C. Dynes and J.M. Rowell, J. Appl. Phys. 41 (1970), p. 1915.

[75] J. Rodríguez Contreras, "Ferroelectric Tunnel Junctions", Dissertation der Universität zu Köln, Eigenverlag Forschungszentrum Jülich, Jülich (2004); J. Rodriguez Contreras "Ferroelectric Tunnel Junctions", ISBN-13: 9783893363681; January 2004.

[76] J. Rodríguez Contreras, H. Kohlstedt, U. Poppe, R. Waser, C. Buchal and N.A. Pertsev, Appl. Phys. Lett. 83 (2003), p. 4595.

[77] R. Meyer and R. Waser, J. Appl. Phys. 100 (2006), p. 051611.

[78] H. Kohlstedt, N.A. Pertsev, J. Rodríguez Contreras and R. Waser, Phys. Rev. B 72 (2005), p. 125341.

[79] S. Fujisaki, H. Ishiwara and Y. Fujisaki, Appl. Phys. Lett. 90 (2007), p. 162902.

[80] K. Asadi, D.M. de Leeuw, B. de Boer and P.W.M. Blom, Nat. Mater. 7 (2008), p. 547.

[81] S. Fujisaki, H. Ishiwara and Y. Fujisaki, Appl. Phys. Express 1 (2008), p. 081801.

[82] R.C.G. Naber, C. Tanase, P.W.M. Blom, G.H. Gelinck, A.W. Marsman, F.J. Touwslager, S. Setayesh and D.M. De Leeuw, Nat. Mater. 4 (2005), p. 243.

[83] R.C.G. Naber, M. Mulder, B. de Boer, P.W.M. Blom and D.M. de Leeuw, Org. Electron. 7 (2006), p. 132.

[84] R.C.G. Naber, P.W.M. Blom, G.H. Gelinck and A.W. Marsman, de Leeuw F D.M., Adv. Mater. 17 (2005), p. 2692.

[85] G.H. Gelinck, A.W. Marsman, F.J. Touwslager, S. Setayesh, D.M. De Leeuw, R.C.G. Naber and P.W.M. Blom, Appl. Phys. Lett. 87 (2005), p. 092903.

[86] R.C.G. Naber, B. de Boer, P.W.M. Blom and D.M. de Leeuw, Appl. Phys. Lett. 87 (2005), p. 203509.

[87] R.C.G. Naber, J. Massolt, M. Spijkman, K. Asadi, P.W.M. Blom and D.M. de Leeuw, Appl. Phys. Lett. 90 (2007), p. 113509.

[88] S. Wi, N. Senthilkumar and S.W. Rhee, J. Mater. Sci-Mater. Electron. 19 (2008), p. 45.

[89] W.J. Choi, S.H. Noh, D.K. Hwang, J.M. Ch, S.J. Jang, E. Kim and S. Im, Electrochem. Solid State Lett. 11 (2008), p. H47.

[90] K. Muller, K. Henkel, I. Paloumpa and D. Schmeiber, Thin Solid Films 515 (2007), p. 7683.

[91] C.A. Nguyen, P.S. Lee, N. Ng, H. Su, S.G. Mhaisalkar, J. Ma and F.Y.C. Boey, Appl. Phys. Lett. 91 (2007), p. 042909.

[92] C.A. Nguyen, P.S. Lee and S.G. Mhaisalkar, Org. Electron. 8 (2007), p. 415.

[93] K.N.N. Unni, R. de Bettignies, S. Dabos-Seignon and J.M. Nunzi, Mater. Lett. 59 (2005), p. 1165.

[94] K.N.N. Unni, R. de Bettignies, S. Dabos-Seignon and J.M. Nunzi, Appl. Phys. Lett. 85 (2004), p. 1823.

[95] S.H. Lim, A.C. Rastogi and S.B. Desu, J. Appl. Phys. 96 (2004), p. 5673.

[96] L. Malin, I. Stolichnov and N. Setter, J. Appl. Phys. 102 (2007), p. 114101.

[97] S.H. Noh, W. Choi, M.S. Oh, D.K. Hwang, K. Lee, S. Im, S. Jang and E. Kim, Appl. Phys. Lett. 90 (2007), p. 253504.

[98] T.J. Reece, S. Ducharme, A.V. Sorokin and M. Poulsen, Appl. Phys. Lett. 82 (2003), p. 142.

[99] S. Ducharme, T.J. Reece, C.M. Othon and R.K. Rannow, IEEE Trans. Dev. Mater. Reliab. 5 (2005), p. 720.

[100] M. Fiebig, J. Phys. D: Appl. Phys. 38 (2005), p. R123.

[101] C. Binek, A. Hochstrat, X. Chen, P. Borisov, W. Kleemann and B. Doudin, J. Appl. Phys. 97 (10) (2005), p. C514.

[102] C. Binek and B. Doudin, J. Phys. Condens. Matter 17 (2005), p. L39. 